\title{
Maturity of children to consent to medical research: the babysitter test
}

Gideon Koren, Daphna Birenbaum Carmeli, Yoram S Carmeli, and Robert Haslam The Hospital for Sick Children, Toronto, the University of Toronto, the Hebrew University, ferusalem, and Haifa University, Israel

\section{Authors' abstract}

The age of maturity of children to consent for medical research is under debate, as different authorities regard the capacity of young teenagers as either satisfactory or not to grant consent without parental participation in the process. The present paper contrasts the generally accepted guideline for ethics in paediatric research in Canada with what the same children are allowed and expected to be able to do as babysitters. This comparison reveals deep incongruences in the way the maturity of the same children is appreciated for two different tasks.

\section{Introduction}

While there is some variability in what different jurisdictions define as the appropriate age for consent by a child, western societies have created a gradual system which, on the one hand deems that young children (for example six years of age) are unable to consent to any medical procedure (therapy or research) and, on the other hand, that older adolescents may assume responsibility for full consent (for example 16 years of age). The rationale underlying these restricted rights of children stems from prevailing perceptions about the nature of maturation. While the cognitive potential of a nine-year-old is not necessarily different from the same child five years later, his life experience and emotional maturity may be entirely different.

The concept of protecting children from potential adverse consequences of therapies or research procedures may bear the risk of orphaning them from the prospect of benefit from such modalities. In a variety of situations, the need to obtain parental consent may exclude teenagers from research (see Table 1), which often cannot be effectively accomplished in other age groups. While society places severe restrictions on what procedures researchers can undertake with minors, it is of interest to verify whether the same principles are adhered to in defining other everyday children's

\section{Key words}

Ethics; research; maturity; children. activities, where maturity is crucial. The act of babysitting is a powerful example of a responsibility given to minors by parents and teachers, where the inherent risk associated with the job seems to be accepted by society.

Not only does babysitting require children to take immense responsibility and exhibit maturity, there are now official courses given to 10-12-year-old children, usually in their schools. Although these courses are usually not part of a formal academic curriculum, they have been endorsed by boards of education and parent/teacher associations, suggesting that babysitting activities are acceptable for $11-$ year-old youngsters, and that the content of the given course is what society expects an average 11year-old to apply when she/he is babysitting.

In the present analysis we wish to contrast the 'state of the art' ethical discourse concerning children's consent to research, with expectations of the same children in their role as babysitters. Our analysis reveals deep incongruences in society's perception of a child's maturity with respect to participation in research as compared to its perception of the maturity required in assuming the role of babysitter. We suggest that contemporary ethical standards may be divorced from reality, and as a result, deprive minors of important rights.

\section{Table 1}

Some examples of research procedures unlikely to be performed if parental consent is needed:

1) Epidemiological and intervention studies of sexually transmitted diseases in sexually active adolescents whose parents are not aware of these activities.

2) Studies on sexual behavioural patterns and contraception methods in sexually active adolescents.

3) Studies on effective contraception strategies in sexually active adolescents.

4) Epidemiological and intervention studies on drug abuse in adolescents. 


\section{Consent and assent in paediatric research}

To prevent atrocities such as those committed by the Nazis in their research with prisoners, the Nuremberg Code insisted that voluntary informed consent must be obtained from all subjects (1). This excluded minors and mentally handicapped and unconscious individuals, who cannot legally consent. If the Nuremberg Code were to be executed literally, research in children could never be ethically performed. Acknowledging this deficiency, the Helsinki Declaration (2) permitted consent in these classes of individuals by parents, guardians or legally authorized representatives. This is presently the view accepted by governments and medical associations worldwide.

Because most children are not legally entitled to consent, the issue of proxy consent, given by parents and guardians, is extremely sensitive, with extensive debate on the nature of the procedure for which a proxy can approve. On the one extreme there are ethicists who submit that one should not touch persons unless they consent to be touched. Ramsey disapproves of research in any non-consenting subject, such as a child, even if no risk is involved (3). McCormick, on the other hand, presumes that the child, if capable, would consent in many such instances (4), and therefore proxy consent is valid. Moreover, as members of 'a moral community', children, according to McCormick, are obligated to contribute to the advance of health and welfare of other members of society. This view is countered by ethicists who claim that unlike adults, children do not have societal obligations and therefore they have no obligation to contribute to society in an unconsented way. According to Freedman, because children are not independent, they have no right to be left alone, but rather the right to be taken care of (5). Therefore proxy consent is not an issue once the risk-benefit questions have been dealt with. A different view is voiced by Ackerman who submits that a child tends to follow 'the course of action that is recommended by the adults who are responsible for the child's wellbeing' (6). Hence, participation in research should not be different from many other activities guided by parents and guardians. At the other extreme of this debate, Gaylin submits that it should be a parental moral obligation to support their children's participation in research (7). According to him, parents and children refusing participation in research should be instructed on the topic of social responsibility. In the following paragraphs we will survey the approach currently found acceptable by the western world to the varying degrees of a child's ability to assent/consent to medical research.

\section{ASSENT}

It is now widely accepted that in addition to parental agreement to enroll their son or daughter into a study, the child should also express such agreement. Assent should be obtained from children who are legally not capable of consent, but who understand the purpose, risks and benefits of the study. The American Academy of Pediatrics regards children with an intellectual level of seven years of age or older as capable of giving such affirmation. When the intellectual age cannot be approximated, the chronological age of seven is considered as the cutting point. A working group of the British Institute of Medical Ethics concurred with this view, saying that 'non therapeutic' research should not be performed on a child older than seven years of age who refuses to participate (8). It is acknowledged by the American Academy of Pediatrics that there may be situations where seeking assent may inflict a high degree of stress on the child because of the nature of the information. In such cases, the academy leaves it to an ethics committee to waive the need for assent after considering what is in the best interests of the child. A task force established by the Canadian National Council of Bioethics in Human Research has recently conceded that assent should be sought from children aged seven to 14 years of age who 'agree voluntarily in the absence of full comprehension, to the action or suggestion of another' (9), while only parents/ guardians are able to give consent.

Relatively few studies have addressed the appropriate age for assent. In a study by Schwartz, the perceptions of children with growth hormone deficiency were assessed. The investigator found that despite multiple discussions on the reason for their hospitalization, none of the children younger than 11 years was aware that the hospitalization was for research purposes (10). Lewis and colleagues approached elementary-school children aged six to nine years of age, to describe the details of a study of influenza vaccine. The children were then encouraged to ask questions. The authors found that all the data required to understand the risks, benefits, and mechanics of the study were sought by the children aged seven to nine years of age (but not the six-yearolds) through their questions. Subsequently, about half refused to participate, and only 15 per cent of the parents of those who did not refuse, signed the consent form (11). The authors interpreted these results as showing that children from seven to nine years of age are capable of comprehending and refusing a research project. It is argued by others, however, that this study does not show individual responses (8). It was argued that although children as a group had elicited the requisite information to form a decision, that did not prove that any child could do so independently: the results did not necessarily reflect the maturity or the capacity to understand even a simple research procedure on the part of all children.

\section{CONSENT BY MINORS}

Weithorn and Campbell examined the correlation between children's development and their competence to give informed decisions about medical 
treatment (but not in a research context). They found that 14-year-old adolescents demonstrated competence levels comparable to adult study groups. Nine-year-old children were similar to adults in measures of competence, although they scored significantly lower on understanding and rationality. Because these tests were performed on white, middle-class, healthy and cognitively normal children, the generalizability of these results is not clear (12). In summarizing available data, Nicholson and his team (8) submit that there are two 'significant turning points' for children who meet average developmental level for their chronological age. At about seven years of age, children reach a level of knowledge about their health which makes it possible to communicate with them about health issues. By the age of 14 years, adolescents achieve a level of competence to make decisions about their health. This cut-off age has been recognized by the South African legislature as the age beyond which a child may be able to consent to the removal of blood, skin or other tissue 'which is replaceable by natural processes of repair for any therapeutic or scientific purpose', without parental consent (13). In the United Kingdom, the Medical Research Council has defined 12 years of age as the cut-off point above which the competence of a child to consent can be assessed based on comprehension, and below which the child would be incompetent in all circumstances (14).

\section{CONSENT BY EMANCIPATED MINORS}

Emancipated minors may consent without the need for parental consent. These are adolescents who are entitled to legal consent because of their status, which includes marriage, parenthood, being a college student who is not living at home, or being a runaway who refuses to provide identification. Generally, these adolescents are managing their own financial affairs and not living with their parents.

\section{CONSENT BY MATURE MINORS}

The mature minor is deemed to be capable of giving consent for medical treatment in several American states. It is a requirement that the treatment will have a direct benefit to the minor, and that the minor is near majority; (for example at least 15 years of age in Oregon and 14 in Alabama). The mature minor must exhibit an understanding of the procedures to be undertaken. In some jurisdictions, (for example, Mississippi) a mature minor is not identified by age but rather by competency to understand the medical problem and its treatment, including the concepts of risk and benefits. These allowances have been designed to permit appropriate treatment for minors who have venereal diseases, are pregnant or who are drug abusers, where parental permission would violate the minors' privacy and prevent them from seeking crucial medical treatment. The question of waiving parental consent to research involving emancipated or mature minors is much more difficult, because, unlike treatment, the research often does not bear direct benefit to the minor.

The American Academy of Pediatrics submits that waiver of parental permission should be considered only if the risk is minimal, the research addresses questions that can be answered only in this population, and that the treatment for the medical condition could be given to the minors based on their consent only. For example, a new antibiotic treatment for gonorrhoea in adolescents meets the above conditions, as do new approaches to treat adolescents' abuse of drugs. The maturity and competency of the minor to understand the procedures, risks and benefits must be carefully evaluated. In a study conducted by Janofsky and Starfield, 75 per cent of researchers said they would use their clinical judgement to evaluate whether the child had sufficient maturity to assent. The other respondents based their decision on a range of age cut-offs between five and 15 years of age (15). The investigator must determine whether the minor agrees to involve the parents, and must never assume $a$ prior that the parents are uninvolved. In fact, it has been argued that the very reasons that have brought minors to be involved in research dealing with their sexuality (for example, pregnancy termination venereal diseases) may not suggest autonomy bu rather a lack of judgement of some of thes youngsters, which has caused them to suffe complications needing medical care (16).

In summary, the different nature and processes of consent constitute some of the unique ethical characteristics of paediatric research. They often pose difficult dilemmas for research ethics committees, as well as for parents and children. The increasing number of different lifestyles adopted by adolescents continuously challenge societal judgement of what might be the appropriate cut-off ages for affirmation, both at the consent and assent levels. When this is coupled with our increasing understanding of children's maturation, it becomes apparent that societal views on children's participation in the consent process will require continuous re-evaluation.

\section{The babysitter course}

The babysitter course is taught as an after-hour class in schools throughout Canada and in the United States. Although it is delivered by a variety of different organizations, for the present analysis we have decided to follow the course provided by the Canadian Red Cross, a major national health organization. The course was developed by the Canadian Red Cross Society in 1988, 'aware of the ever-increasing need for responsible and competent babysitters' with the aim of enabling 'young people to develop the self-assurance, knowledge and skills required to carry out their babysitting duties 
effectively' (17). The instructors may be adults such as teachers, nurses, parents, or even secondary school students knowledgeable about childcare such as youth group leaders and experienced babysitters. A first-aid instructor is required for the 'handling emergencies' section. In the instructor's guidebook the course is presented as 'designed for students 11-15 years old' but adds that 'although ten-yearolds are very young for the responsibilities of babysitting, many do babysit at that age. Ten-yearolds may attend the course, at the discretion of the instructor'. In most cases the initiators for conducting the course in a specific school are parents and members of a parent teacher association.

The authors of the course make the assumption that various difficulties, even hazards, may arise during any 'ordinary' babysitting session. These may result as a consequence of both routine as well as exceptional situations. Hence, guidelines concerning safety comprise a major part of the curriculum and are persistently reiterated throughout (for example 'the babysitter's main concern is safety'. 'Accidents are the leading cause of death among Canadian children'.)

About one-half of the course deals with everyday situations and chores. The authors draw the pupil's attention to routine situations such as temper tantrums, children's fears, sibling fights, or holding an infant ('IMPORTANT: a newborn head and neck must always be supported'). The 12-year-old babysitter is expected to be able to: change a nappy ('Never leave an infant unattended while changing a diaper. Slide your finger between the diaper and the infant's body when you are putting the safety pins in'); to feed a baby ('Never leave a baby alone with a bottle when feeding; the baby could throw up and choke on the vomit'); to make sure the baby's crib is locked properly, and to bathe a child (the guide does specify that 'for safety reasons, it is recommended that the babysitter be responsible for washing a baby's hands and face, but not for bathing' (bold in the book). Yet, there are detailed instructions regarding the bathing of 'children over two years' ('Remain with the child the entire time he is in the water. If the phone rings, either let it ring or wrap the child in a towel and take him with you'). It appears then, that although it is not recommended it is acknowledged as quite probable that a ten to 15year-old babysitter may bathe a child over two years old.

A chapter entitled Accident Prevention is entirely devoted to possible hazards which the babysitter may have to face. These include harm caused by fire, by poisonous, explosive or corrosive domestic substances and various accidental injuries. The instructor's guide stresses that: 'Most of the injured are under five', and that: 'The highest causes of death for children under age 14, drowning and infant choking, are the result of lack of supervision'. While this chapter centres on the prevention of accidents, the following section, concerning the handling of emergencies, is geared to qualify babysitters to: 'Give first-aid for life-threatening and minor injuries; evacuate children safely from a burning house; react safely to intruding strangers in person and over the phone; decide whether an illness is serious, and what action to take, and to recognize the signs of child abuse and know what to do if child abuse is suspected'. The future babysitter is instructed how to deal with - amongst other things - serious bleeding, head and bone injuries, rescue-breathing and choking. In the course's final test there are 11 questions on this chapter, such as:

'You are giving rescue-breathing to a six-month-old. How often should you blow in (the child's mouth)'?
a: Once every three seconds
b: Once every five seconds
c: Once every ten seconds

If a child has been hit by a car you should:

a: Keep him lying in the street; have two adults stop traffic

b: Get two adults to help you carry him off the street c: Have the child walk off the street, to see if he's all right

Abdominal thrusts (the Heimlich Manoeuvre) are used for children who are:

a: Partly choking but are able to talk

b: Cannot breathe at all, are turning blue

c: Both a and b'

The babysitter is expected to be able to react to emergencies according to a rational sequence of priorities. Another expectation of the babysitter involves possible threats by intruders. The explicit instruction given: 'Say that the parents are busy and can't come to the phone/door. Do not say that you are a babysitter or that the parents are out' - sheds an interesting light on adults' perception concerning the arrangement of babysitting. The babysitter is here instructed to conceal the fact that no adult is currently available and to create an impression that someone else, seemingly more capable of dealing with intruders, is nearby. The babysitter is required to demonstrate defiance and mature judgement, as well as the ability to deceive.

The concluding chapter deals with child abuse. Here the babysitter is told that cases may arise in which she or he would be the person to protect a child from abuse by his own parents or relatives. The babysitter is instructed to report her/his suspicion to an adult she or he trusts. The authors of the babysitter course are, of course, not the initiators but those responding to an existing practice of employing 11-year-old babysitters for younger children. While it 
is conceivable that most babysitting jobs do not entail most of the skills mentioned, we nevertheless find it significant that such skills could be needed.

\section{Somé comparative references}

By the nature of the babysitting task, at least two children are involved: the babysitter and the younger child. The babysitter, presumably between the ages of ten and 15, is quite explicitly expected to function in a way usually expected of mature individuals; ie to be capable of dealing not only with regular activities requiring discretion and responsibility (such as feeding or bathing a baby) but also with acute emergencies, potentially bearing severe and even life-threatening implications (from rescue-breathing to a stranger knocking on the back door).

The other child or children involved are the younger ones, cared for by the babysitter. Unaware of the situation, they are exposed to various potential hazards. In other words, the infant or young child is under the direct care of another child who is not deemed by society to be mature enough to consent to medical research but who is deemed able to make very skilled and difficult decisions on behalf of another individual.

Belonging primarily in the category defined by ethicists as 'those very young children, apparently most in need of protection from harm ... (birth seven years of age)' (9), they are left to be supervised by those belonging to the 'older' sub-category (ten 14 years of age) described by the same ethicists as 'those children in the mid-range of maturation, somewhat capable of protecting themselves from harm, still needy with regard to nurture as not-yetadult' (9). The assumptions underlying the babysitting course are strikingly incongruent with the widely accepted notions concerning children's vulnerability, which are taken for granted in other domains of life, and expressed clearly in the recent report of the task force of the National Council on Bioethics in Human Research on research involving children (9). The very children who are considered too immature to judge for themselves whether they may participate in a medical research procedure, and whose assent is no more than partial, are considered competent to deal with emergency situations, seemingly much more complicated and demanding, involving not only themselves but also another child, younger and more helpless than themselves.

Unlike the child participating in medical research, the babysitter is often left on her/his own without proper explanation and/or information. In the research situation, the participating child may decline and withdraw from participation at any given moment, irrespective of the research procedure. In contrast (17), 'the babysitter must not walk away unless her/his job is completed, even (or rather especially) if troubles arise.' Also in clear contradistinction to the research situation, in which rewards are allowed only if not mentioned prior to the conclusion of the child's participation and if not contingent on the completion of the experimental procedure, the babysitter, too young to be allowed adult work-rights and officially not allowed to work at all, usually takes the job primarily for the sake of earning money. The discrepancy may seem even greater if we consider the fact that both situations refer to exactly the same population: general Canadian society.

The difference can be defined in terms of two common parameters - the magnitude and the probability of possible harm. It appears that ethicists have given explicit priority to the magnitude, as opposed to the probability, of potential harm, while those accepting babysitting by minors have placed a relatively heavier weight on probability. Thus, although the young babysitter may, indeed, have to face difficult problems, the likelihood of such situations occurring is apparently considered small enough so as not to rule out this common practice.

One may argue that the likelihood that a young babysitter will need to exhibit such high levels of skill and maturity while on duty is marginal, and hence merely theoretical. However, illustrating two paediatric emergencies, we will document that this is not the case, and that there are genuine attendane risks for both the babysitters as well as the childrer cared for by them.

1) About five per cent of Canadian children between the ages of two and six years have asthma (18). Every year 400,000 Canadian children are born, and hence there are about 80,000 two - sixyear-old children who have asthma. Estimating a mean of two asthmatic attacks per year, at least one beginning at night (this is probably an underestimate for night prevalence), up to 80,000 asthmatic attacks may begin at night in this age group. Estimating that, on average, Canadian parents use babysitters once monthly, then about 2,700 asthmatic attacks would begin during the nights these children are cared for by babysitters. If, on average, the babysitter stays only until midnight, (ie one third of the night), at least 900 Canadian babysitters may have to deal with an asthmatic attack every year.

2) The Sudden Infant Death Syndrome (SIDS) occurs at rates of $2 / 1000$ liveborn infants, primarily during the first six months of life (19). Making the same assumptions presented above, every year about 26 Canadian babies will have SIDS on nights while in the care of a babysitter. While it is very likely that even an adult babysitter, or the parents themselves, would not be able to prevent these tragic events, the trauma to the 12-year-old babysitter may be immense. For example, in most cases a coroner's inquiry will include the babysitter to rule out foul play. It can easily be argued that the risk for the minor in this case is much more serious than for most paediatric research protocols, when consent by a minor is sought. 
Our analysis suggests that while adults in general accept children to be mature enough to supervise younger children in extremely dangerous situations, the same children are judged to be too immature to consent to research.

It may be argued that 'children do, in any case, babysit' and it is therefore sensible to instruct them how to do it right. However, society does not accept children's behaviours just because they are being practised (for example smoking, drugs, etc).

The incongruency between consent to research and babysitting are even more disturbing when the financial aspects of the two activities are considered. Researchers are explicitly not allowed to offer children or their families financial incentives aimed at increasing the likelihood of participation in research. Conversely, money is the driving force and a paramount condition in babysitting. In our institution several protocols dealing with adolescents with chronic conditions (for example cystic fibrosis) have failed due to the inability to enrol adolescents, while there were no problems in recruiting a healthy control group, which consisted of young adults who were paid at an hourly rate. In one instance, a researcher asked permission to pay adolescents with chronic illness at a similar rate to the adult volunteers. Permission was granted and he was able to complete his study almost immediately.

In summary, our analysis uncovers deep inconsistencies in society's perception of a child's maturity with respect to participation in research, as compared to assuming the role of a babysitter. The data suggest that contemporary ethical standards may be divorced from reality and, as a result, deprive minors of important rights. A new look is needed at the ability of minors to consent to research which presently cannot be performed without parental consent (see Table 1), as much of the advance in adolescent medicine will have to stem from research conducted with this age group.

Gideon Koren, $M D, A B M T$, FRCP $(C)$, is a career scientist at the Ontario Ministry of Health and Director of the Division of Clinical Pharmacology at the Hospital for Sick Children, Toronto. Robert Haslam, MD, FRCP(C) is Professor and Chairman of Pediatrics in the Hospital for Sick Children, Toronto. Dr Koren is a member of the Human Subject Review Committee, the Department of Pediatrics and Research Institute, the Hospital for Sick Children, Toronto. Daphna Birenbaum Carmeli, $M A$, is a visiting scientist in the Department of Pediatrics and Pharmacology, University of Toronto, and a PhD student in the Department of Sociology and Anthropology, the Hebrew University, ferusalem, Israel. Yoram S Carmeli, $\mathrm{PhD}$, is Professor in the Department of Sociology and Anthropology, Haifa University, Israel.

\section{References}

(1) The Nuremberg Code. In: (Duncan A S, Dunstan G R, Welbourn R B, eds.) Dictionary of medical ethics (2nd ed). London: Darton, Longman and Todd, 1981: 130-132.

(2) World Medical Association. Declaration of Helsinki. Recommendations guiding physicians in biomedical research involving human subjects. (Adopted, Helsinki 1964; Amended, Tokyo 1975, and Venice 1983).

(3) Ramsey P. Unconsented touching and the autonomy absolute. IRB: $A$ review of human subjects research 1980; 2, 10: 9-10.

(4) McCormick R A. Proxy consent in the experimentation situation. Perspectives in biology and medicine 1974; 18: 2-20.

(5) Freedman B. A moral theory of informed consent. Hastings Center report 1979; 5, 4: 32-39.

(6) Ackerman T F. Fooling ourselves with child autonomy and assent in nontherapeutic clinical research. Clinical research 1979; 27: 345-348.

(7) Gaylin W. Competence: no longer all or none. In: Gaylin W, Macklin R, eds. Who speaks for the child? New York: Plenum Press, 1982: 27-54.

(8) Nicholson R H. Medical research with children: ethics, law and practice. Oxford: Oxford University Press, 1986.

(9) Consent panel task force. Research involving children: final report. Ottawa, Ontario: The National Council for Bioethics in Human Research, 1991.

(10) Schwartz A H. Children's concepts of research hospitalization. New England journal of medicine 1972; 287: 589-592.

(11) Lewis C E, Lewis M A, Ifekwunigue M. Informed consent by children and participation in an influenza vaccine trial. American journal of public health 1978; 68: 1079-1082.

(12) Weithorn L A, Campbell S B. The competency of children and adolescents to make informed treatment decisions. Child development 1983; 9: 285-292.

(13) Burchell J M. Nontherapeutic medical research in children. South African law journal 1978; 95: 193-216.

(14) Medical Research Council. Responsibility in investigations on human subjects. In: Report of the Medical Research Council for the year 1962-63. London: HMSO, 1964: 21-25.

(15) Janofsky J, Starfield B. Assessment of risk in research on children. Fournal of pediatrics 1981; 98: 842846.

(16) Koren G, Smith B. Case presentations. In: Koren G, ed. Textbook of ethics in pediatric research. Florida: Kreiger, 1993.

(17) Rughlow Y. The babysitter course. Student handbook and instructor's guide. Toronto, Ontario: The Canadian Red Cross Society, 1988.

(18) Rudolph A M. Pediatrics (18th ed). Norwalk, Connecticut: Appleton and Lange, 1987: 437.

(19) Kraus J F L. Methodologic considerations in the search for risk factors unique to sudden infant death syndrome. In: Tilden $T$ J, Raeder $L \quad M$, Steinschneider A, eds. Sudden infant death syndrome. New York: Academic, 1983: 43. 